\title{
Reduction Rates for Higher Americium Oxidation States in Nitric Acid
}

Fuel Cycle Research \& Development

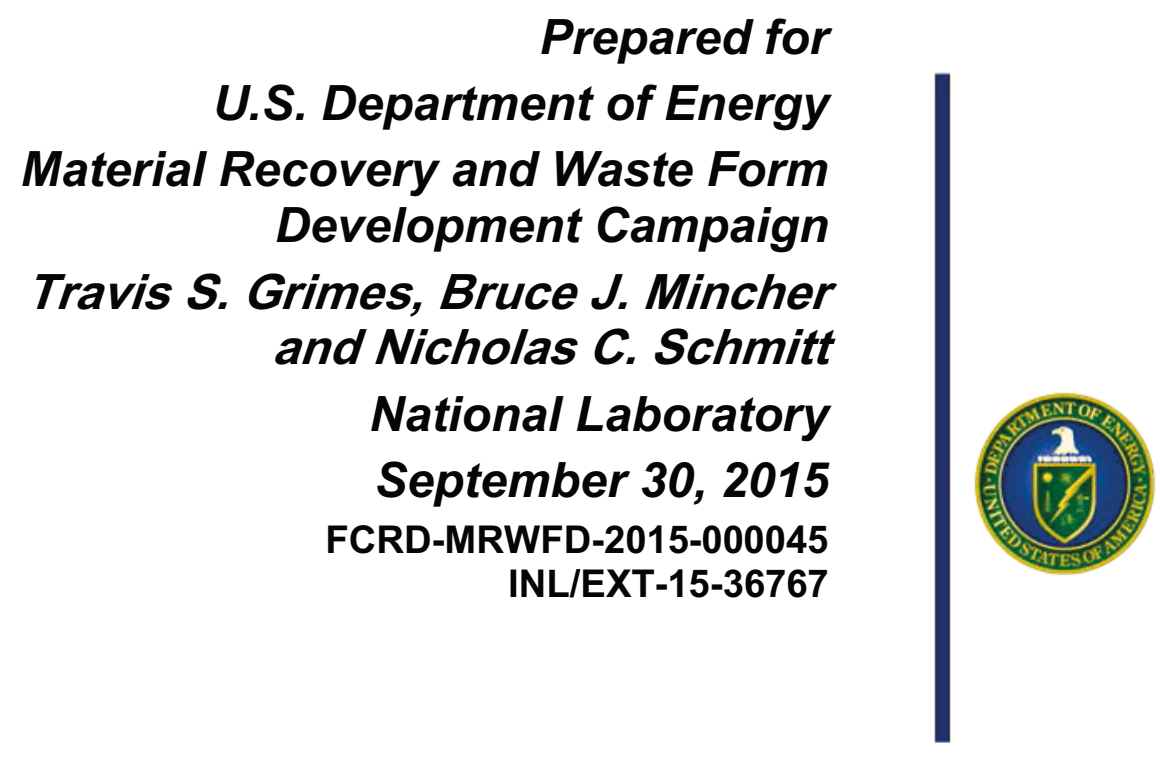




\section{DISCLAIMER}

This information was prepared as an account of work sponsored by an agency of the U.S. Government. Neither the U.S. Government nor any agency thereof, nor any of their employees, makes any warranty,

expressed or implied, or assumes any legal liability or responsibility for the accuracy, completeness, or usefulness, of any information, apparatus, product, or process disclosed, or represents that its use would not infringe privately owned rights. References herein to any specific commercial product, process, or service by trade name, trade mark, manufacturer, or otherwise, does not necessarily constitute or imply its endorsement, recommendation, or favoring by the U.S. Government or any agency thereof. The views and opinions of authors expressed herein do not necessarily state or reflect those of the U.S. Government or any agency thereof. 


\section{SUMMARY}

The stability of hexavalent americium was measured using multiple americium concentrations and nitric acid concentrations after contact with the strong oxidant sodium bismuthate. Contrary to our hypotheses $\mathrm{Am}(\mathrm{VI})$ was not reduced faster at higher americium concentrations, and the reduction was only zero-order at short time scales. Attempts to model the reduction kinetics using zero order kinetic models showed $\mathrm{Am}(\mathrm{VI})$ reduction in nitric acid is more complex than the autoreduction processes reported by others in perchloric acid. The classical zero-order reduction of $A m(V I)$ was found here only for short times on the order of a few hours. We did show that the rate of $\mathrm{Am}(\mathrm{V})$ production was less than the rate of $\mathrm{Am}(\mathrm{VI})$ reduction, indicating that some $\mathrm{Am}(\mathrm{VI})$ undergoes two electron-reduction to $\mathrm{Am}(\mathrm{IV})$. We also monitored the Am(VI) reduction in contact with the organic diluent dodecane. A direct comparison of these results with those in the absence of the organic diluent showed the reduction rates for Am(VI) were not statistically different for both systems. Additional americium oxidations conducted in the presence of $\mathrm{Ce}(\mathrm{IV}) / \mathrm{Ce}(\mathrm{III})$ ions showed that $\mathrm{Am}(\mathrm{VI})$ is reduced without the typical growth of $\mathrm{Am}(\mathrm{V})$ observed in the systems sans Ce ion. This was an interesting result which suggests a potential new reduction/oxidation pathway for $\mathrm{Am}$ in the presence of $\mathrm{Ce}$, however these results were very preliminary and will require additional experiments to understand the mechanism by which this occurs. Overall these studies have shown that hexavalent americium is fundamentally stable enough in nitric acid to run a separations process. However, the complicated nature of the reduction pathways based on the system components is far from being rigorously understood. 


\section{CONTENTS}

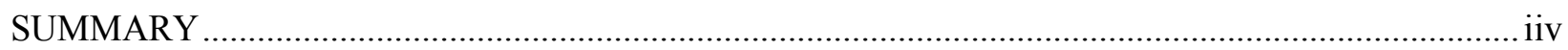

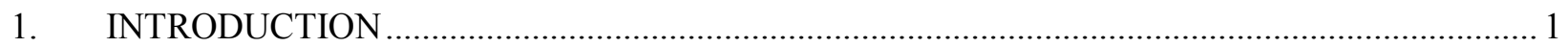

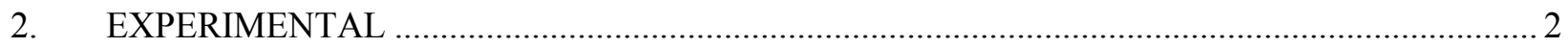

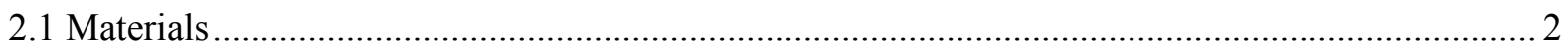

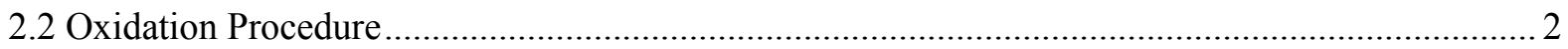

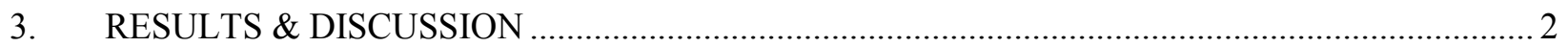

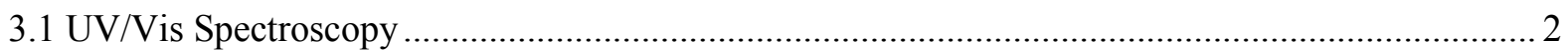

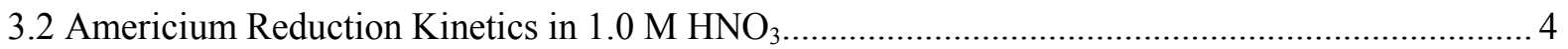

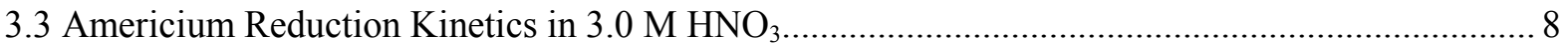

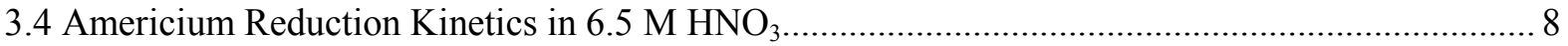

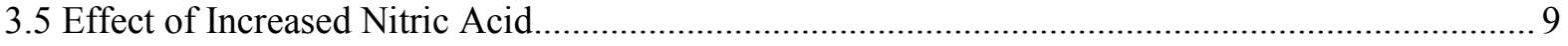

3.6 Electrolytically Determined Americium(VI) Reduction Rates. ............................................... 10

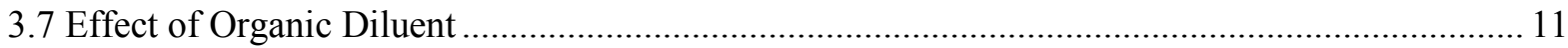

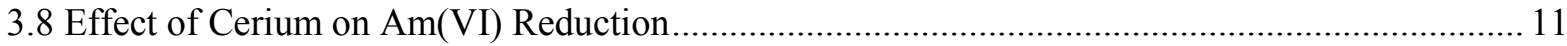

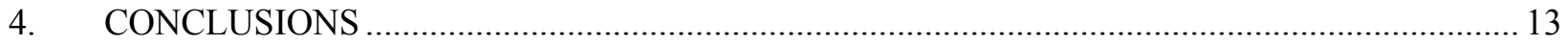

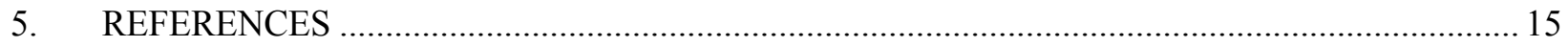




\section{FIGURES}

Figure 1. UV/Vis absorption spectra highlighting the multiple Am oxidation states at the corresponding wavelengths. The solution contains $4.0 \mathrm{mM}$ total Am in $1.0 \mathrm{M} \mathrm{HNO}_{3}$ contacted with sodium bismuthate for $24 \mathrm{~h}$. The arrows indicate absorbance peak growth or reduction over a $48 \mathrm{~h}$ period.

Figure 2. Absorbance peaks used to calculate the concentration of each americium oxidation state for all nitric acid systems. These data represent $2.0 \mathrm{mM} \mathrm{Am}$ in $1.0 \mathrm{M} \mathrm{HNO}_{3}, 72 \mathrm{~h}$ data collection.

Figure 3. Concentration vs. time plots for (A) $1.0 \mathrm{mM} \mathrm{Am}$, (B) $2.0 \mathrm{mM} \mathrm{Am}$, and (C) $4.0 \mathrm{mM}$ $\mathrm{Am}$ in $1.0 \mathrm{M} \mathrm{HNO}_{3}$. Squares indicate measured values and solid line indicates zero-order model.

Figure 4. Analysis of the kinetic data using (A) first order (B) second order kinetic models. The plots presented are for $4.0 \mathrm{mM} \mathrm{Am}$ in $1.0 \mathrm{M} \mathrm{HNO}_{3}$. Squares indicate measured data with model shown as solid line.

Figure 5. The autoreduction of $A m(V I)$ and production of $A m(V)$ in a solution containing 1.0 $\mathrm{mM}$ total Am and $1.0 \mathrm{M} \mathrm{HNO}_{3}$. The absorptions used to calculate Am concentration are as follows: (口) $999 \mathrm{~nm}, \mathrm{Am}(\mathrm{VI}),(\mathrm{O}) 666 \mathrm{~nm}, \mathrm{Am}(\mathrm{VI}),(\triangle) 718 \mathrm{~nm}, \mathrm{Am}(\mathrm{V})$.

Figure 6. Normalized Am(VI) kinetic curves in 1.0, 3.0, and 6.5 M nitric acid to highlight the stability of the Am(VI) oxidation state as nitric acid in increased.

Figure 7. Characteristic absorption spectra for oxidized americium in the presence of $\mathrm{Ce}(\mathrm{IV})$.

The absorbances represent $1.0 \mathrm{mM} \mathrm{Am}$ and $5.0 \mathrm{mM}$ Ce in $6.5 \mathrm{M} \mathrm{HNO}_{3}$. 


\section{TABLES}

Table 1. Relevant molar extinction coefficients $\varepsilon\left(\mathrm{M}^{-1} \mathrm{~cm}^{-1}\right)$ for various americium oxidation states used to calculate concentrations in these studies. The values reported are a combination of previously determined values by this group and gathered from the literature. 3

Table 2. Calculated Am(VI) reduction and $A m(V)$ growth rates from the linear portion of the zero order kinetic plots for the $1.0 \mathrm{M}$ nitric acid systems. The kinetic rates were calculated using data $0-2 \mathrm{~h}$.

Table 3. Calculated Am(VI) reduction and $A m(V)$ growth rates from the linear portion of the zero order kinetic plots for the $3.0 \mathrm{M}$ nitric acid systems. The kinetic rates were calculated using data $0-2 \mathrm{~h}$.

Table 4. Calculated $\mathrm{Am}(\mathrm{VI})$ reduction and $\mathrm{Am}(\mathrm{V})$ growth rates from the linear portion of the zero order kinetic plots for the $6.5 \mathrm{M}$ nitric acid systems. The kinetic rates were calculated using data $0-2 \mathrm{~h}$

Table 5. Reduction/Growth rates for $\mathrm{Am}(\mathrm{VI}) / \mathrm{Am}(\mathrm{V})$ in contact with a $1 \mathrm{~mL}$ aliquot of dodecane using a $2 \mathrm{~h}$ time increment. The americium solution contained $4.0 \mathrm{mM}$ Am in $6.5 \mathrm{M} \mathrm{HNO}_{3}$.

Table 6. Reduction rates for $\mathrm{Am}(\mathrm{VI})$ in the presence of Ce(IV) using a $2 \mathrm{~h}$ time increment. The americium solution contained $1.0 \mathrm{mM} \mathrm{Am} / 5.0 \mathrm{mM}$ Ce in $6.5 \mathrm{M} \mathrm{HNO}_{3}$ 


\section{ACRONYMS}

$\begin{array}{ll}\text { INL } & \text { Idaho National Laboratory } \\ \text { PTFE } & \text { Polytetrafluoroethylene (Teflon) } \\ \text { UV/Vis } & \text { Ultra Violet/Visible }\end{array}$




\section{SIGMA TEAM FOR ADVANCED ACTINIDE RECYCLE: REDUCTION RATES FOR HIGHER OXIDATION STATES OF AMERICIUM}

\section{INTRODUCTION}

The first work describing the autoreduction of the higher oxidation states of americium was reported by Asprey and Stephanou in 1950. [1] In that report, hexavalent ${ }^{241} \mathrm{Am}$ was produced by peroxydisulfate oxidation and its reduction was observed spectrophotometrically in $1 \mathrm{M} \mathrm{HClO}_{4}$. It was reported that $\mathrm{Am}(\mathrm{VI})$ reduced to $\mathrm{Am}(\mathrm{V})$ in linear fashion. The production of $\mathrm{Am}(\mathrm{III})$ was low until all Am(VI) was reduced to $A m(V)$, suggesting a sequential reduction. The reduction rates were zero-order with respect to the high valent americium concentration but first-order with respect to the total americium concentration (0.9-33mM), being approximately $0.046 \mathrm{~h}^{-1}$, and $0.023 \mathrm{~h}^{-1}$, respectively. The effect of hydrogen ion concentration was thought to be small, while the faster rate for the Am(VI) to Am(V) reduction was attributed to only one equivalent being required for that reaction. Hall and Markin (1957) [2] reported similar kinetics for 2.6-8.0 mM total americium in $0.2 \mathrm{M} \mathrm{HClO}_{4}$, and reported 0.031 and $0.012 \mathrm{~h}^{-1}$ for $\mathrm{Am}(\mathrm{VI})$ and $\mathrm{Am}(\mathrm{V})$, respectively. The authors attributed this so-called autoreduction to reaction with the $\mathrm{H}_{2} \mathrm{O}_{2}$ product of americium $\alpha$-decay. The attribution is reasonable, since the main reducing agent in $\alpha$ irradiated aqueous solution is expected to be $\mathrm{H}_{2} \mathrm{O}_{2}$, which has a yield in neutral water of $0.1 \mu \mathrm{mol} \mathrm{J} \mathrm{J}^{-1}$. [3] The bimolecular rate constant for the reaction of $\mathrm{Am}(\mathrm{VI})$ with $\mathrm{H}_{2} \mathrm{O}_{2}$ at $25^{\circ} \mathrm{C}$ in perchloric acid was reported as $\left(4.592 \pm 0.007-0.12 \pm 0.01 \log \left[\mathrm{H}^{+}\right]\right)$, resulting in a value of $5.15 \times 10^{4} \mathrm{M}^{-1} \mathrm{~s}^{-1}$ in $0.1 \mathrm{M}$ acid. [4] The reaction is shown in eq 1:

$\mathrm{AmO}_{2}{ }^{2+}+\mathrm{H}_{2} \mathrm{O}_{2} \rightarrow \mathrm{AmO}_{2}^{+}+{ }^{\cdot} \mathrm{HO}_{2}+\mathrm{H}^{+}$

It should be noted that the rate constant for the reaction of $\mathrm{Am}(\mathrm{V})$ with $\mathrm{H}_{2} \mathrm{O}_{2}$ was reported by Zaitsev et al. (1960) [5] to have a similar value of $5.33 \times 10^{4} \mathrm{M}^{-1} \mathrm{~s}^{-1}$ in $0.1 \mathrm{M} \mathrm{HClO}_{4}$. However, it is known empirically that $\mathrm{Am}(\mathrm{V})$ is much more stable than $\mathrm{Am}(\mathrm{VI}),[1,2,6]$ possibly indicating that the reported rate constant for the $\mathrm{Am}(\mathrm{V}) / \mathrm{H}_{2} \mathrm{O}_{2}$ reaction is in error. Nitrous acid is produced from the direct radiolysis of nitrate anion and nitric acid [7]:

$\mathrm{HNO}_{3} \rightarrow \mathrm{HNO}_{2}+{ }^{\circ} \mathrm{O}$

$\mathrm{NO}_{3}^{-} \rightarrow \mathrm{NO}_{2}^{-}+{ }^{\circ} \mathrm{O}$

The yield of $\mathrm{HNO}_{2}$ increases with the concentration of the irradiated nitric acid, although the yields reported have varied. The value probably falls in the range $(0.017) *\left[\mathrm{HNO}_{3}\right]$ to $0.031 *\left[\mathrm{HNO}_{3}\right] \mu \mathrm{mol} \mathrm{J}{ }^{-1}$. $[8,9]$ It should also be a reducing agent for $\mathrm{Am}(\mathrm{VI})$, based on analogy with its reduction of $\mathrm{Np}(\mathrm{VI})$, [9] however, no rate constants have been reported. Nitrous acid and $\mathrm{H}_{2} \mathrm{O}_{2}$ effects on americium redox chemistry are partially mitigated by their reaction with each other: [7]

$\mathrm{HNO}_{2}+\mathrm{H}_{2} \mathrm{O}_{2} \rightarrow \mathrm{NO}_{3}^{-}+\mathrm{H}_{3} \mathrm{O}^{+} \quad\left(4.6 \times 10^{3}[\mathrm{H}+] \mathrm{M}^{-1} \mathrm{~s}^{-1}\right)$

Based on an estimated yield of $0.02 *\left[\mathrm{HNO}_{3}\right]$ the concentration of $\mathrm{HNO}_{2}$ would become competitive with $\mathrm{H}_{2} \mathrm{O}_{2}$ at $\mathrm{HNO}_{3}$ concentrations of $>\sim 5 \mathrm{M}$. It can be seen that the rate of the reaction in eq. 4 should also be enhanced at higher acid concentrations. This, in combination with greater production of $\mathrm{HNO}_{2}$ suggests that $\mathrm{Am}(\mathrm{VI})$ should be more stable at higher acidity. 
Only two chemical reagents are routinely used for the preparation of $\mathrm{Am}(\mathrm{V})$ and/or $\mathrm{Am}(\mathrm{VI})$ in acidic solution. They are ammonium peroxydisulfate, $\left(\mathrm{NH}_{3}\right)_{2} \mathrm{~S}_{2} \mathrm{O}_{8}$ and sodium bismuthate, $\mathrm{NaBiO}_{3}$. Of these, only bismuthate is effective in nitric acid concentrations greater than about $0.3 \mathrm{M}$. Therefore, sodium bismuthate was used here to prepare $\mathrm{Am}(\mathrm{VI})$ over a range of nitric acid and americium concentrations, using routine procedures, [10] and the reduction of $\mathrm{Am}(\mathrm{VI})$ and subsequent appearance of $\mathrm{Am}(\mathrm{V})$ and Am(III) were monitored over time using UV/Vis spectroscopy. It was hypothesized that Am(VI) reduction would be zero-order in $\mathrm{Am}(\mathrm{VI})$ concentration, and faster at higher total americium concentrations, if radiolytically-produced $\mathrm{H}_{2} \mathrm{O}_{2}$ is the reducing agent. It was further hypothesized that Am(VI) would be more stable at high acid concentrations due to the scavenging of $\mathrm{H}_{2} \mathrm{O}_{2}$ by radiolytically produced $\mathrm{HNO}_{2}$. Preliminary results regarding the effect of dodecane and $\mathrm{Ce}(\mathrm{IV})$ on the reduction rate of $\mathrm{Am}(\mathrm{VI})$ are also reported.

\section{EXPERIMENTAL}

\subsection{Materials}

Sodium bismuthate (93\% ACS reagent grade) was purchased from Chemsavers. Nitric acid (67-70\% Omnitrace) was purchased from Fisher Scientific. The nitric acid solutions in these studies were made by dilution of the concentrated acid and standardized by titration with a standardized sodium hydroxide (50\% w/w, Sigma Aldrich) solution using a phenolphthalein indicator (2\% in ethanol, Sigma Aldrich). The 10 $\mathrm{mL}$ BD syringes (luer-lok tip) and $25 \mathrm{~mm}$ syringe filters $(0.2 \mu \mathrm{m}$ PTFE membrane, Pall Lifesciences) were purchased from VWR. The americium solutions were made by diluting INL stock solutions with the standardized nitric acid solutions to obtain the desired metal ion concentrations and acidities.

\subsection{Oxidation Procedure}

To probe the effect of americium concentrations on the reduction rates, oxidation experiments were conducted with $[\mathrm{Am}]_{\text {total }}=1.0,2.0$ and $4.0 \mathrm{mM}$. The stability of Am(VI) at higher acidities was explored with oxidations at $\left[\mathrm{HNO}_{3}\right]=0.1,1.0,3.0$, and $6.5 \mathrm{M}$. Contact times were optimized to obtain maximum oxidation of Am(III) to Am(VI), $24 \mathrm{~h}$ for 1.0 and $3.0 \mathrm{M} \mathrm{HNO}_{3}, 2 \mathrm{~h}$ for $6.5 \mathrm{M} \mathrm{HNO}_{3}$. The $0.1 \mathrm{M} \mathrm{HNO}_{3}$ system yielded only $\mathrm{Am}(\mathrm{V})$ after a $24 \mathrm{~h}$ contact, and therefore no data is reported for that acid concentration.

Oxidation of Am(III) to Am(VI) was achieved by contacting $60 \mathrm{mg}$ sodium bismuthate per $1 \mathrm{~mL}$ of Am solution. The sodium bismuthate is sparingly soluble and must be filtered away from the americium solution. After contact, the americium/sodium bismuthate solutions were loaded into the $10 \mathrm{~mL}$ syringe using Pasteur pipettes (the use of glass limits contact of americium solutions with the potentially reducing environment introduced by plastics) and filtered through the syringe filter. The solutions free of particulates were then loaded into quartz cuvettes and the absorption spectra were collected using a CARY 6000i.

\section{RESULTS \& DISCUSSION}

\subsection{UV/Vis Spectroscopy}

The characteristic absorptions for the various oxidation states of americium are 503 and 813 for Am(III), 513 and $718 \mathrm{~nm}$ for $\mathrm{Am}(\mathrm{V})$, and 666 and $999 \mathrm{~nm}$ for $\mathrm{Am}(\mathrm{VI})$. These absorption intensities are converted to concentration for each americium species present in solution using the Beer-Lambert law shown in eq 5:

$\mathrm{A}=\varepsilon b c$ 
Where $\mathrm{A}=$ absorbance, $\varepsilon=$ extinction coefficient or molar absorptivity, $\mathrm{b}=$ path length (cuvette width), $\mathrm{c}$ $=$ concentration of the absorbing species. The americium concentrations are plotted as a function of time to determine the reduction rate and kinetic order of the reactions. Figure 1 shows the unique absorption bands for each oxidation state of americium in these studies.

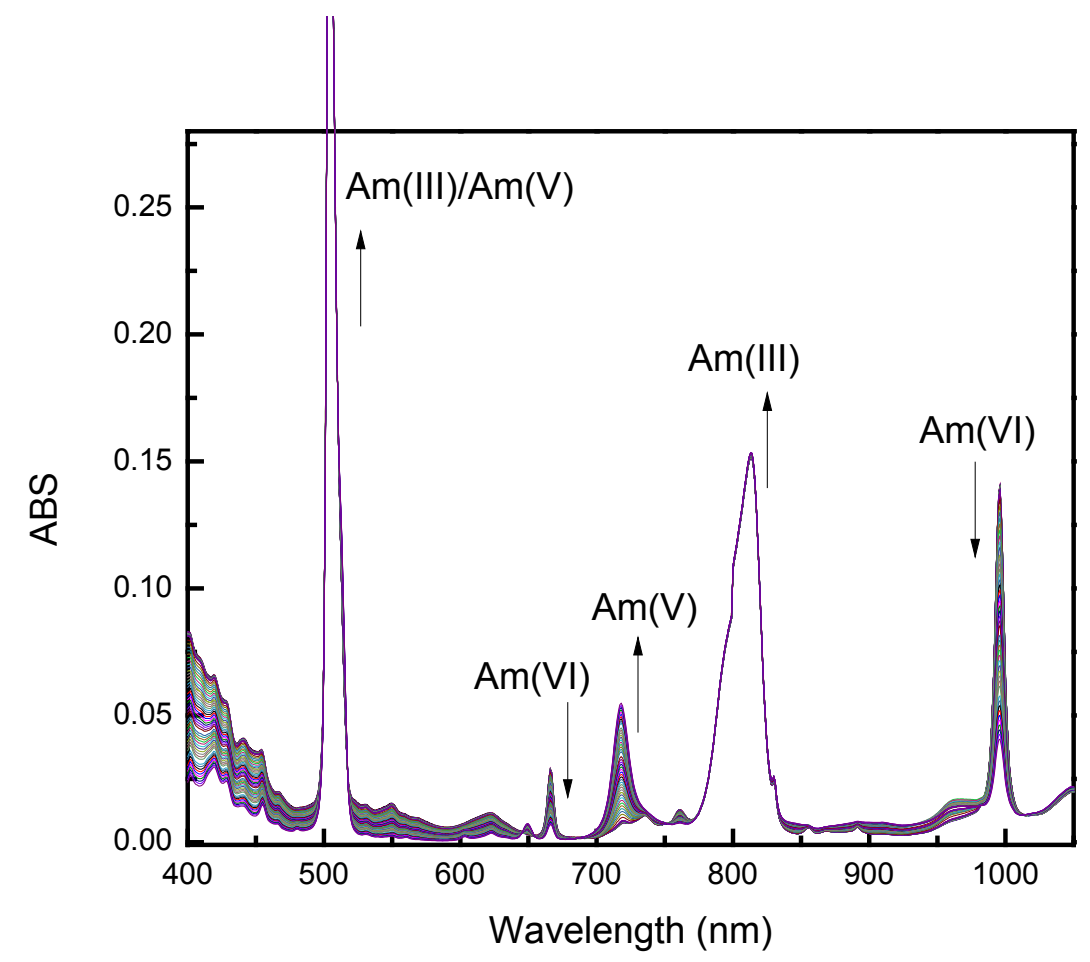

Figure 1. UV/Vis absorption spectra highlighting the multiple Am oxidation states at the corresponding wavelengths. The solution contains $4.0 \mathrm{mM}$ total $\mathrm{Am}$ in $1.0 \mathrm{M} \mathrm{HNO}_{3}$ contacted with sodium bismuthate for $24 \mathrm{~h}$. The arrows indicate absorbance peak growth or reduction over a $48 \mathrm{~h}$ period.

The known extinction coefficients for the various oxidation states of americium are shown in table 1 .

Table 1. Relevant molar extinction coefficients $\varepsilon\left(\mathrm{M}^{-1} \mathrm{~cm}^{-1}\right)$ for various americium oxidation states used to calculate concentrations in these studies. The values reported are a combination of previously determined values by this group and gathered from the literature. $[6,11,12]$

\begin{tabular}{ccccccc|} 
[HNO3], M & & $\mathrm{Am}(\mathrm{III})$ & $\mathrm{Am}(\mathrm{V})$ & \multicolumn{2}{c|}{$\mathrm{Am}(\mathrm{VI})$} & \\
\hline \hline & & $\boldsymbol{\varepsilon} 503$ & $\boldsymbol{\varepsilon 5 1 3}$ & $\boldsymbol{\varepsilon 7 1 8}$ & $\boldsymbol{\varepsilon} 666$ & $\varepsilon 999$ \\
\cline { 3 - 7 } 0.1 & LWCC & 313.5 & 38.1 & & & \\
0.1 & $1 \mathrm{~cm}$ & 386.7 & & 72.5 & 27.9 & \\
1 & & 320 & 40.3 & & & 83.3 \\
6.5 & & 272 & 36.4 & & & \\
\hline
\end{tabular}


It is worth noting that due to the limited data in the literature, the extinction coefficients used in this study to calculate oxidized americium concentrations were used outside of the nitric acid concentrations they were determined in. Therefore some error is likely due to the media effects of increasing or decreasing the background electrolytes across the range of nitric acid concentrations used for these studies. However, at this time no widely accepted set of extinction coefficients for these peaks exists.

\subsection{Americium Reduction Kinetics in $1.0 \mathrm{M} \mathrm{HNO}_{3}$}

A $24 \mathrm{~h}$ contact with sodium bismuthate yielded $\sim 50 \%$ conversion of $\mathrm{Am}(\mathrm{III})$ to $\mathrm{Am}(\mathrm{VI}), \sim 2 \%$ to $\mathrm{Am}(\mathrm{V})$, the remaining $\sim 8 \%$ staying $\mathrm{Am}(\mathrm{III})$ in the $1.0 \mathrm{M} \mathrm{HNO}_{3}$ system for all three americium concentrations. These data also show the Am(VI) was still detectable up to $55 \mathrm{~h}$ in $1.0 \mathrm{M} \mathrm{HNO}_{3}$ regardless of total americium concentration. Figure 2 shows a representative sample of baseline corrected absorbance peaks used to determine concentration of the various Am species in all the nitric acid systems. The data show the disappearance of the $999 \mathrm{~nm}$ and $666 \mathrm{~nm}$ peaks (Am(VI)) as the $718 \mathrm{~nm}$ and $513 \mathrm{~nm}$ peaks grow in $(\mathrm{Am}(\mathrm{V}))$ as well as the growth of the 813 and the $503 \mathrm{~nm}$ peaks (Am(III)).
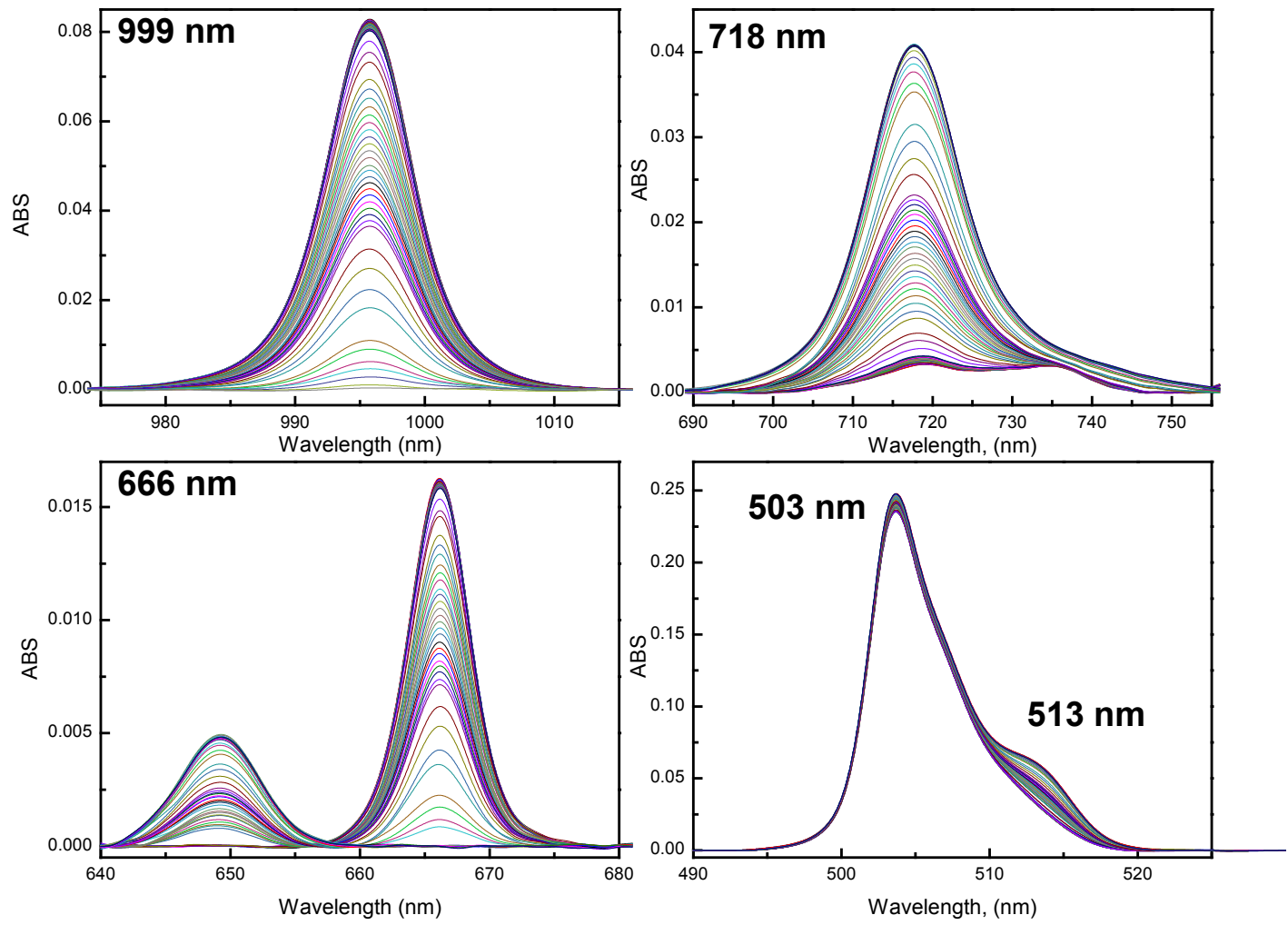

Figure 2. Absorbance peaks used to calculate the concentration of each americium oxidation state for all nitric acid systems. These data represent $2.0 \mathrm{mM}$ Am in $1.0 \mathrm{M} \mathrm{HNO}_{3}, 72 \mathrm{~h}$ data collection.

Previous literature $[1,2]$ suggests that Am(VI) autoreduction occurs by reaction with its own radiolysis products, and should result in zero order kinetics with respect to the Am(VI) concentration, thus 
producing linear plots of $[\mathrm{Am}(\mathrm{VI})]$ vs. time. The change in absorbance peak heights illustrated in figure 2 were compared to zero order kinetic models, as shown in figure 3, for 1.0, 2.0 and 4.0 $\mathrm{mM}$ americium in $1.0 \mathrm{M} \mathrm{HNO}_{3}$ solution.
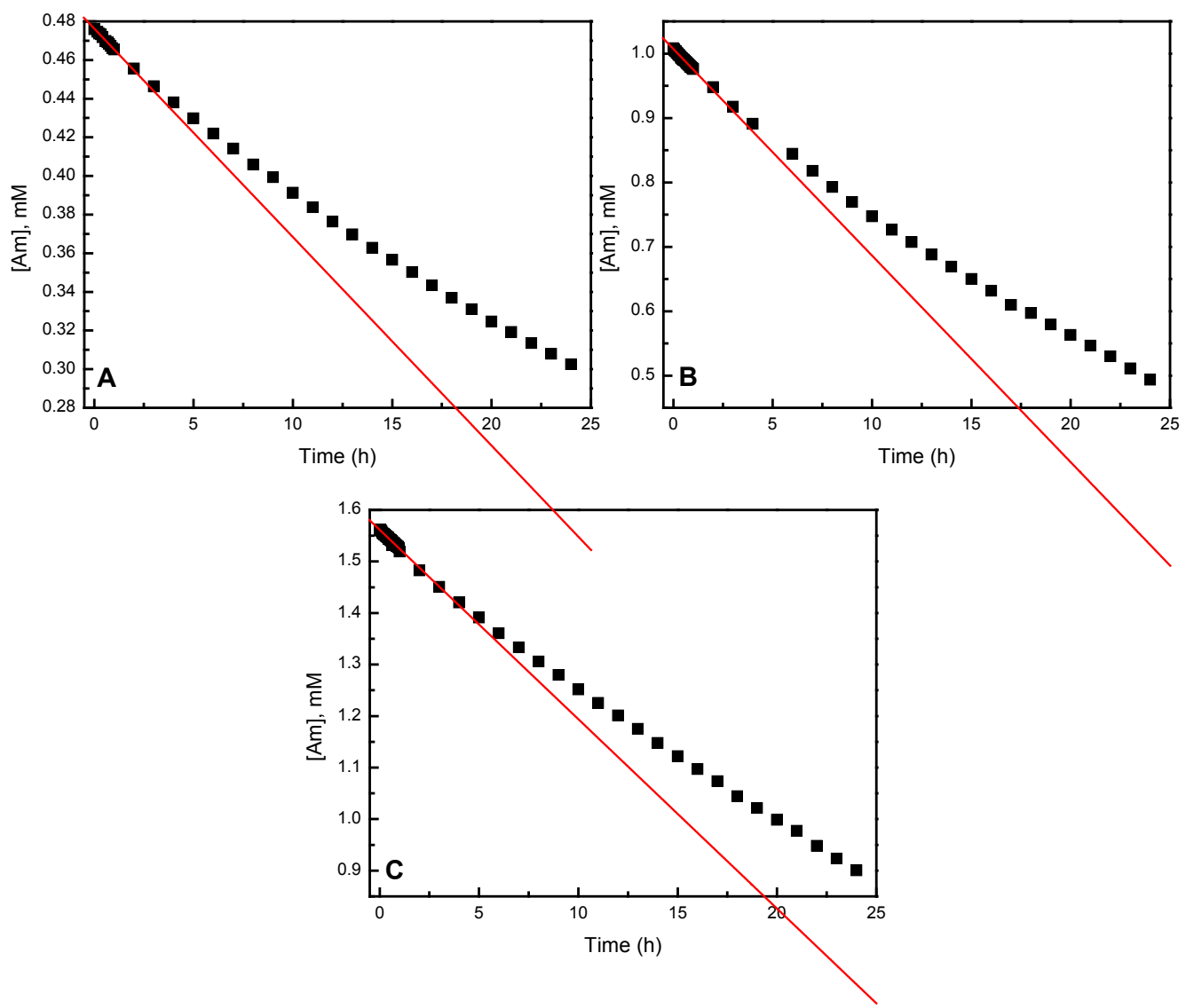

Figure 3. Concentration vs. time plots for (A) $1.0 \mathrm{mM} \mathrm{Am}$, (B) $2.0 \mathrm{mM} \mathrm{Am}$, and (C) $4.0 \mathrm{mM}$ Am in 1.0 $\mathrm{M} \mathrm{HNO}_{3}$. Squares indicate measured values and solid line indicates zero-order model.

The data in figure 3 are linear at shorter time scales up to nearly $5 \mathrm{~h}$, then show significant departure from linearity for all three concentrations of americium for times up to $25 \mathrm{~h}$. The initial linearity is probably the radiolytic autoreduction previously reported, while at longer time scales additional reactions become important. These data were therefore also treated using first and second order models. The results of these treatments are shown in figure 4, and did not produce linear plots consistent with first or second order kinetics. These results suggest mixed order kinetics. This would be consistent with departure from the initial zero order reduction as the radiolytically produced nitrous acid builds up to react with hydrogen peroxide, to decrease the rate of americium reduction. The disproportionation rate of $A m(V)$ would also be expected to increase as the $A m(V)$ concentration increases, further complicating the reduction kinetics. 

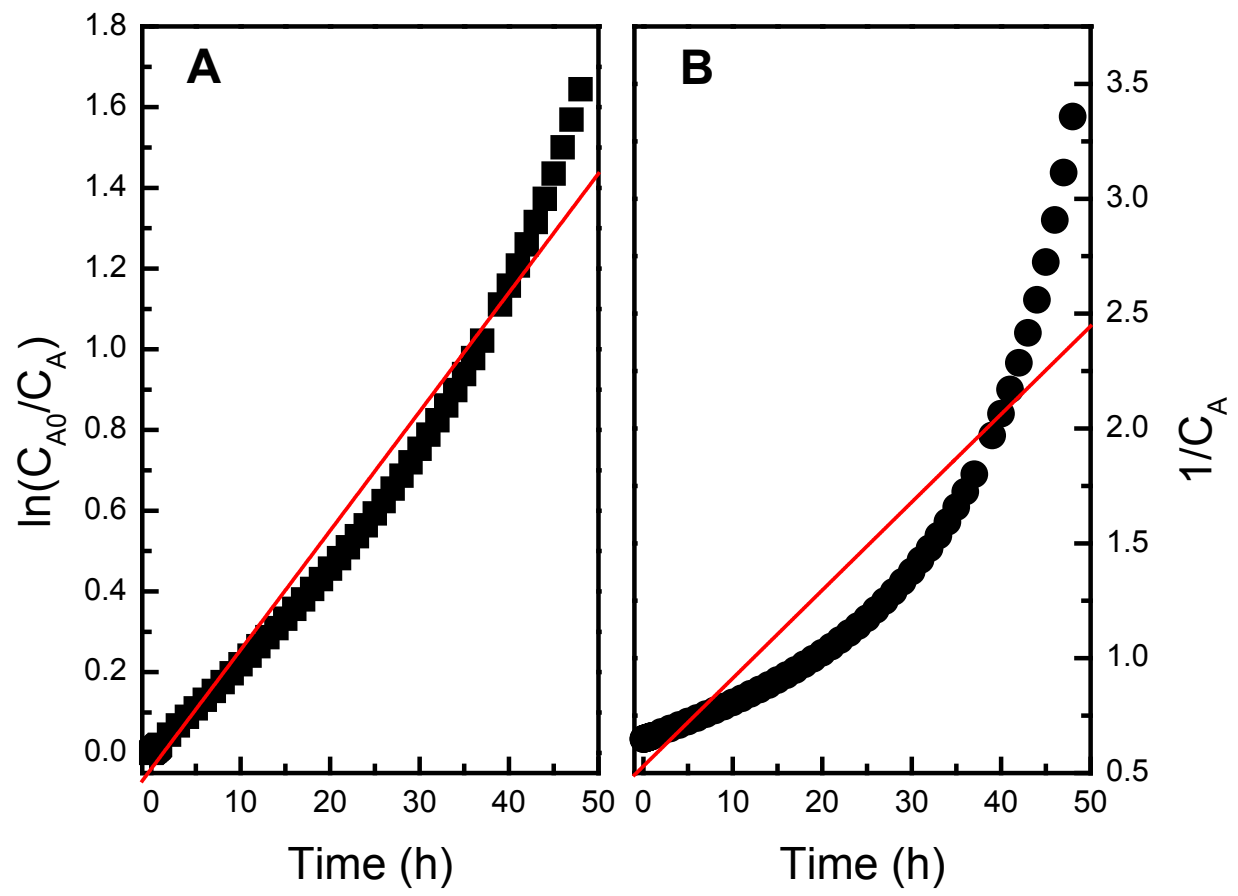

Figure 4. Analysis of the kinetic data using (A) first order (B) second order kinetic models. The plots presented are for $4.0 \mathrm{mM}$ Am in $1.0 \mathrm{M} \mathrm{HNO}_{3}$. Squares indicate measured data with model shown as solid line.

Although the data show complicated chemistry and the single order kinetic models are not adequate to model the Am(VI) reduction, the data in figure 3 do show linearity initially. If this linearity is considered zero order then information may be obtained by fitting the data over the $0-2 \mathrm{~h}$ time scale. The obtained slopes may be divided by the total americium concentration to obtain reduction rates that are first order with respect to total americium concentration. An example of these plots and corresponding slopes are shown in figure 5. 


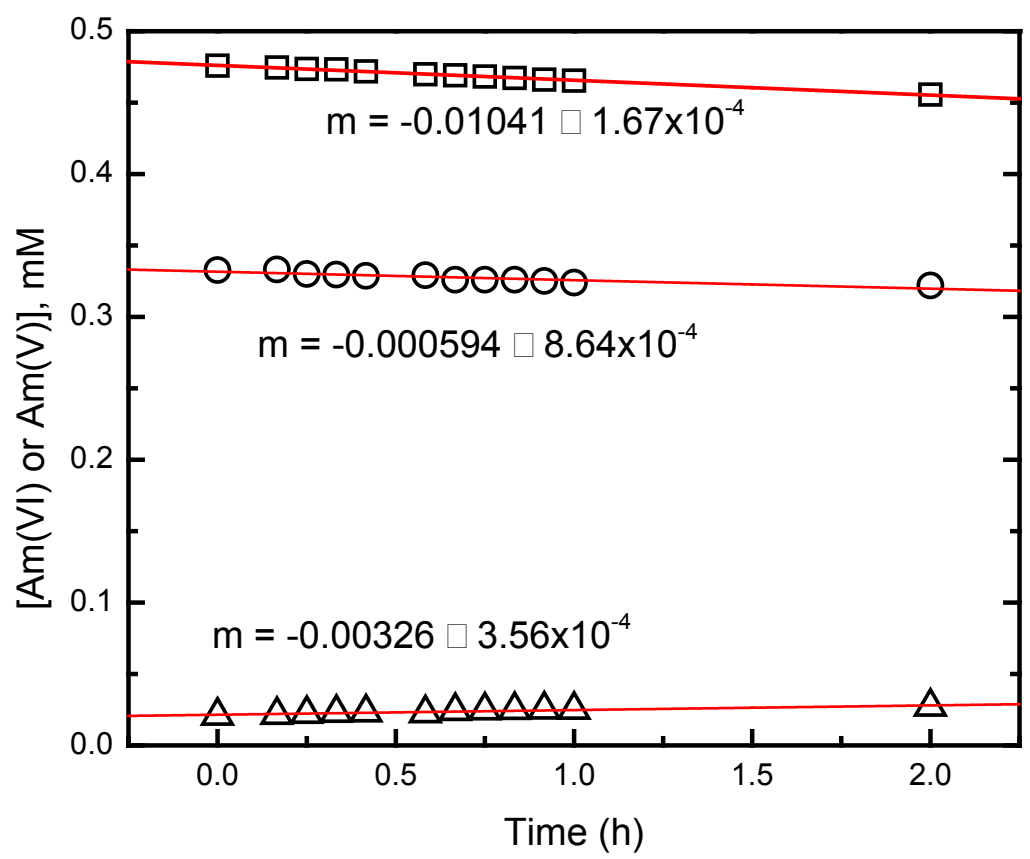

Figure 5. The autoreduction of $\mathrm{Am}(\mathrm{VI})$ and production of $\mathrm{Am}(\mathrm{V})$ in a solution containing $1.0 \mathrm{mM}$ total Am and 1.0 $\mathrm{M} \mathrm{HNO}_{3}$. The absorptions used to calculate the Am concentration are as follows: ( $\square$ ) 999 $\mathrm{nm}, \mathrm{Am}(\mathrm{VI}),(\mathrm{O}) 666 \mathrm{~nm}, \mathrm{Am}(\mathrm{VI}),(\triangle) 718 \mathrm{~nm}, \mathrm{Am}(\mathrm{V})$.

The results for the three americium concentrations in $1.0 \mathrm{M} \mathrm{HNO}_{3}$ are reported in table 1. It can be seen that the Am(VI) rates calculated based on the $666 \mathrm{~nm}$ peak are not in agreement with those of the $999 \mathrm{~nm}$ peak. This is attributed to the large error associated with the slope determination based on this relatively weak absorbance. The data reported in table 1 show an extinction coefficient of $83.3 \mathrm{M}^{-1} \mathrm{~cm}^{-1}$ for $999 \mathrm{~nm}$ and $27.9 \mathrm{M}^{-1} \mathrm{~cm}^{-1}$ for $666 \mathrm{~nm}$; this represents a greater absorbance for the $999 \mathrm{~nm}$ peak by a factor of 3 . The greater absorbance leads to more precise conversion of absorbance to concentration. However, it can be seen that increasing the americium concentration does not have any effect on the autoreduction rates of $\mathrm{Am}(\mathrm{VI})$, at least over this concentration range. It can also be seen that the rate of $\mathrm{Am}(\mathrm{V})$ production is about half the rate of $A m(V I)$ reduction. This suggests that reduction routes for Am(VI) that bypass $\mathrm{Am}(\mathrm{V})$ may occur. This will be discussed in more detail later.

Table 2. Calculated $A m(V I)$ reduction and $A m(V)$ growth rates from the linear portion of the zero order kinetic plots for the $1.0 \mathrm{M}$ nitric acid systems. The kinetic rates were calculated using data $0-2 \mathrm{~h}$.

\begin{tabular}{|c|c|c|c|c|c|c|}
\hline \multicolumn{3}{|c|}{999 nm } & $666 \mathrm{~nm}$ & \multicolumn{3}{|c|}{$718 \mathrm{~nm}$} \\
\hline$[\mathrm{Am}]_{\text {total }}, \mathrm{mM}$ & Rate $\left(\mathrm{h}^{-1}\right)$ & \pm 1 sigma & Rate $\left(\mathrm{h}^{-1}\right)$ & \pm 1 sigma & Rate $\left(\mathrm{h}^{-1}\right)$ & \pm 1 sigma \\
\hline 4.0 & 0.008 & 0.002 & 0.005 & 0.001 & 0.004 & 0.001 \\
\hline 2.0 & 0.009 & 0.002 & 0.007 & 0.002 & 0.004 & 0.001 \\
\hline 1.0 & 0.010 & 0.001 & 0.006 & 0.001 & 0.003 & 0.001 \\
\hline
\end{tabular}




\subsection{Americium Reduction Kinetics in $3.0 \mathrm{M} \mathrm{HNO}_{3}$}

A $24 \mathrm{~h}$ contact with sodium bismuthate yielded $\sim 85 \%$ conversion of $\mathrm{Am}(\mathrm{III})$ to $\mathrm{Am}(\mathrm{VI}), \sim 4 \%$ to $\mathrm{Am}(\mathrm{V})$, the remaining $\sim 10 \%$ staying $\mathrm{Am}(\mathrm{III})$ in the $3.0 \mathrm{M} \mathrm{HNO}_{3}$ system for all three americium concentrations. Absorption spectra show that $\mathrm{Am}(\mathrm{VI})$ is detectable up to $72 \mathrm{~h}$ in $3.0 \mathrm{M} \mathrm{HNO}_{3}$ for all the initial americium concentrations studied.

Attempts to model the $\mathrm{Am}(\mathrm{VI})$ reduction in the $3.0 \mathrm{M} \mathrm{HNO}_{3}$ systems using the zero order kinetics proved unsuccessful since the data showed the same curvature present as in the $1.0 \mathrm{M} \mathrm{HNO}_{3}$ systems. The data fitting was again not improved using first or second order kinetic models. The results of those fitting exercises resembled the results shown for $1.0 \mathrm{M} \mathrm{HNO}_{3}$ in figure 4. The kinetic data did once again show linearity in the initial time periods of data collection suggesting autoreduction as found for the $1.0 \mathrm{M}$ systems. The reduction rates for the $3.0 \mathrm{M}$ nitric acid systems are shown in table 2 .

Table 3. Calculated Am(VI) reduction and Am(V) growth rates from the linear portion of the zero order kinetic plots for the 3.0 M nitric acid systems. The kinetic rates were calculated using data 0-2 h.

\begin{tabular}{|c|c|c|c|c|c|c|}
\hline \multicolumn{3}{|c|}{$999 \mathrm{~nm}$} & $666 \mathrm{~nm}$ & \multicolumn{3}{|c|}{$718 \mathrm{~nm}$} \\
\hline$[\mathrm{Am}]_{\text {total, }}, \mathrm{mM}$ & Rate $\left(\mathrm{h}^{-1}\right)$ & \pm 1 sigma & Rate $\left(\mathrm{h}^{-1}\right)$ & \pm 1 sigma & Rate $\left(\mathrm{h}^{-1}\right)$ & \pm 1 sigma \\
\hline 4 & 0.010 & 0.002 & 0.007 & 0.001 & 0.004 & 0.001 \\
\hline 2 & 0.011 & 0.002 & 0.007 & 0.001 & 0.004 & 0.001 \\
\hline 1 & 0.008 & 0.001 & 0.010 & 0.002 & 0.005 & 0.001 \\
\hline
\end{tabular}

In this case the higher Am(VI) yield allows for more confidence in the $666 \mathrm{~nm}$ data, and those results are in better agreement with the $999 \mathrm{~nm}$ results. The rates are similar to those reported for the $1.0 \mathrm{M} \mathrm{HNO}_{3}$ system, Once again it can be seen that the $\mathrm{Am}(\mathrm{V})$ production is about half that of $\mathrm{Am}(\mathrm{VI})$ reduction. It appears from these two data sets that neither the americium concentration or the nitric acid concentration has any effect on the rate of autoreduction of $A m(V I)$. These observations are made with caution for two reasons: 1) only about $8 \%$ of the kinetic data is utilized for these analyses, 2) secondary and tertiary reactions associated with radiolysis may be occurring before the $2 \mathrm{~h}$ limit; at this early stage of analysis, using the linear portion of the data to extract some information was a logical first approximation.

\subsection{Americium Reduction Kinetics in 6.5 $\mathrm{M} \mathrm{HNO}_{3}$}

A $2 \mathrm{~h}$ contact with sodium bismuthate yielded $\sim 85 \%$ conversion of $\mathrm{Am}(\mathrm{III})$ to $\mathrm{Am}(\mathrm{VI}), \sim 14 \%$ to $\mathrm{Am}(\mathrm{V})$, the remaining $\sim 1-2 \%$ staying $\mathrm{Am}(\mathrm{III})$ in the $6.5 \mathrm{M} \mathrm{HNO}_{3}$ system for all three americium concentrations. Absorption spectra show that $\mathrm{Am}(\mathrm{VI})$ is detectable after $110 \mathrm{~h}$ in $6.5 \mathrm{M} \mathrm{HNO}_{3}$ for all the americium concentrations studied.

Consistent with the two previous nitric acid systems, attempts to model the Am(VI) reduction in the 6.5 $\mathrm{M} \mathrm{HNO}_{3}$ using the zero order kinetics also proved unsuccessful. Fitting iterations using first or second order kinetic models again offered no improvement. First and second order kinetic fitting exercises resembled the results shown in figure 4. A small portion of the data did show linearity in the initial time period of collection, out to $2.5 \mathrm{~h}$, consistent with the assumed autoreduction for the two previous systems. Based on this linearity the same analysis was applied to the $6.5 \mathrm{M}$ nitric acid systems. The Am(VI) reduction and $\mathrm{Am}(\mathrm{V})$ production rates for $6.5 \mathrm{M}$ nitric acid are shown in table 3 . 
Table 4. Calculated Am(VI) reduction and Am(V) growth rates from the linear portion of the zero order kinetic plots for the $6.5 \mathrm{M}$ nitric acid systems. The kinetic rates were calculated using data $0-2 \mathrm{~h}$.

\begin{tabular}{|c|c|c|c|c|c|c|}
\hline \multicolumn{3}{|c|}{$999 \mathrm{~nm}$} & $666 \mathrm{~nm}$ & \multicolumn{3}{|c|}{$718 \mathrm{~nm}$} \\
\hline$[\mathrm{Am}]_{\text {total, }} \mathrm{mM}$ & Rate $\left(\mathrm{h}^{-1}\right)$ & \pm 1 sigma & Rate $\left(h^{-1}\right)$ & \pm 1 sigma & Rate $\left(\mathrm{h}^{-1}\right)$ & \pm 1 sigma \\
\hline 4 & 0.012 & 0.003 & 0.005 & 0.001 & 0.003 & 0.001 \\
\hline 2 & 0.011 & 0.003 & 0.007 & 0.001 & 0.004 & 0.001 \\
\hline 1 & 0.009 & 0.002 & 0.006 & 0.002 & 0.004 & 0.001 \\
\hline
\end{tabular}

A comparison of all the calculated Am(VI) reduction rates for $1.0 \mathrm{mM}, 2.0 \mathrm{mM}$, and $4.0 \mathrm{mM}$ americium in 1.0, 3.0, and 6.5 $\mathrm{M} \mathrm{HNO}_{3}$ show consistent overlap at one sigma error with an average rate for Am(VI) reduction around $0.010 \pm 0.001 \mathrm{~h}^{-1}$ using $999 \mathrm{~nm}, 0.007 \pm 0.001 \mathrm{~h}^{-1}$ using the less reliable $666 \mathrm{~nm}$, and an average growth rate for $\mathrm{Am}(\mathrm{V})$ of $0.004 \pm 0.0006 \mathrm{~h}^{-1}$ using $718 \mathrm{~nm}$. It appears that $\mathrm{Am}(\mathrm{V})$ growth rates do not correlate directly to $\mathrm{Am}(\mathrm{VI})$ reduction under any condition. This result is in agreement with those recently reported by Dares et al. [13] in $0.1 \mathrm{M} \mathrm{HNO}_{3}$ using surface functionalized electrodes to electrolytically prepare Am(VI). This work suggests that there is a reduction routes bypassing Am(V) and is discussed in more detail later.

\subsection{Effect of Increased Nitric Acid}

The total kinetic data were collected over long time scales, e.g., up to $110 \mathrm{~h}$. Collecting the kinetic data for this long has shown that $\mathrm{Am}(\mathrm{VI})$ stability increases with increasing nitric acid concentration, as was predicted, likely due to $\mathrm{H}_{2} \mathrm{O}_{2}$ and $\mathrm{HNO}_{2}$ interactions illustrated in equation 4. Figure 6 shows normalized $\mathrm{Am}(\mathrm{VI})$ kinetic curves in 1.0, 3.0, and $6.5 \mathrm{M} \mathrm{HNO}_{3}$. The data in figure 6 clearly show a decrease in the $\mathrm{Am}(\mathrm{VI})$ reduction rate over the long time periods observed for each system. This is also a clear indication that the Am(VI) reduction kinetics are slower with increasing nitric acid concentration. In addition to eq 1 , other potential reduction pathways become important with increasing nitric acid concentration. These reactions involve radiolytically produced nitrous acid and disproportionation reactions of $\mathrm{Am}(\mathrm{V})$.

$2 \mathrm{AmO}_{2}{ }^{2+}+\mathrm{HNO}_{2}+\mathrm{H}_{2} \mathrm{O} \rightarrow 2 \mathrm{AmO}_{2}^{+}+3 \mathrm{H}^{+}+\mathrm{NO}_{3}^{-}$

$3 \mathrm{AmO}_{2}^{+} \rightarrow \mathrm{AmO}_{2}^{2+}+\mathrm{Am}(\mathrm{III})$

Thus, at least at least four pathways contribute to Am(VI), so-called, autoreduction. These are: 1) reduction by reactions with radiolytically-produced free radicals, which happen on a time scale to fast to measure here and which rate should be directly proportionally to the radiation dose rate (in this case directly proportional to the total $[\mathrm{Am}]$ ); 2) reduction by radiolytically-produced $\mathrm{H}_{2} \mathrm{O}_{2} ; 3$ ) reduction by radiolytically-produced $\mathrm{HNO}_{2}$, with these mitigating each other as they grow into solution, and more-so at higher nitric acid concentration; 4) Am(V) disproportionation which increases with increasing [Am(V)] over time. Further there appear to be 1-, and 2-electron reduction pathways for Am(VI). The combined effects of all these reactions almost certainly rules out single order kinetics to describe these systems. Analyzing these types of data will require a more sophisticated approach such as stepwise model building using reactions with known reaction rate constants. 


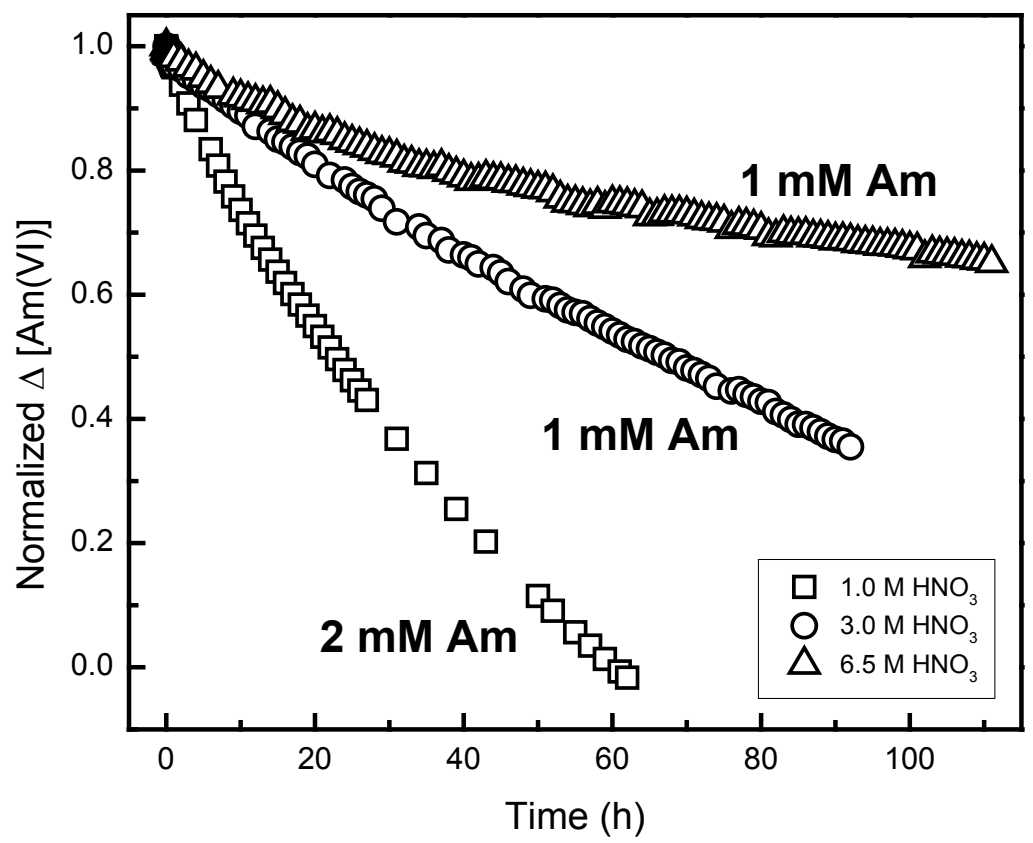

Figure 6. Normalized Am(VI) kinetic curves in 1.0, 3.0, and 6.5 M nitric acid to highlight the stability of the $\mathrm{Am}(\mathrm{VI})$ oxidation state as nitric acid is increased.

\subsection{Electrolytically Determined Americium(VI) Reduction Rates}

A comparison of all the calculated $\mathrm{Am}(\mathrm{VI})$ reduction rates over the linear range for $1.0 \mathrm{mM}, 2.0 \mathrm{mM}$, and $4.0 \mathrm{mM}$ americium in 1.0, 3.0, and 6.5 $\mathrm{M} \mathrm{HNO}_{3}$ show consistent overlap at one sigma error with an average rate for $A m(V I)$ reduction around $0.010 \pm 0.001 \mathrm{~h}^{-1}$ using $999 \mathrm{~nm}, 0.007 \pm 0.001 \mathrm{~h}^{-1}$ using the less reliable $666 \mathrm{~nm}$, and an average growth rate for $\mathrm{Am}(\mathrm{V})$ of $0.004 \pm 0.0006 \mathrm{~h}^{-1}$ using $718 \mathrm{~nm}$. It appears the $\mathrm{Am}(\mathrm{V})$ growth rates do not correlate directly to Am(VI) reduction under any condition. This result is in general agreement with that recently reported by Dares et al. [13] using surface functionalized electrodes to electrolytically prepare Am(VI). Those authors reported a reduction rate for Am(VI) of $2.3 \mathrm{E}-5 \mathrm{~s}^{-1}\left(0.083 \mathrm{~h}^{-1}\right)$ with ingrowth of $\mathrm{Am}(\mathrm{V})$ at $1.6 \mathrm{E}-5 \mathrm{~s}^{-1}\left(0.058 \mathrm{~h}^{-1}\right)$ for a $0.65 \mathrm{mM}$ total americium solution containing initially $85 \% \mathrm{Am}(\mathrm{VI})$, in $0.1 \mathrm{M} \mathrm{HNO}_{3}$. These rates, measured after the applied | potential was turned off, are an order-of-magnitude faster than those reported here for the bismuthate system, at much lower americium and nitric acid concentrations. These authors suggested that Am(VI) had two reduction pathways; a one-electron reduction to $\mathrm{Am}(\mathrm{V})$, and a two-electron reduction to Am(IV). It is not clear why the reduction rate measured here is slower, although the presence of residual oxidant may have a role. 


\subsection{Effect of Organic Diluent}

The stability of Am(VI) was further tested by contact with the common organic diluent, dodecane. A 1 $\mathrm{mL}$ aliquot of dodecane was placed on top of the americium solution in the cuvette and introduced to the spectrometer. The two phases were not agitated to create an emulsion, so any effect on the reduction kinetics introduced by dodecane would be diffusion controlled. The kinetic data were collected for $20 \mathrm{~h}$ and are shown in table 5.

Table 5. Reduction/Growth rates for $\mathrm{Am}(\mathrm{VI}) / \mathrm{Am}(\mathrm{V})$ in contact with a $1 \mathrm{~mL}$ aliquot of dodecane using a $2 \mathrm{~h}$ time increment. The americium solution contained 4.0 $\mathrm{mM}$ Am in 6.5 $\mathrm{M} \mathrm{HNO}_{3}$.

\begin{tabular}{|c|cc|cc|cc|}
\hline \multicolumn{2}{|c}{$999 \mathbf{~ n m}$} & \multicolumn{6}{c}{$\mathbf{6 6 6} \mathbf{~ n m}$} & $\mathbf{7 1 8} \mathbf{~ n m}$ & \\
\hline $\begin{array}{c}{[\text { Am }]_{\text {total }},} \\
\mathrm{mM}\end{array}$ & $\begin{array}{c}\text { Reduction } \\
\text { Rate }\left(\mathrm{h}^{-1}\right)\end{array}$ & \pm 1 sigma & $\begin{array}{c}\text { Reduction } \\
\text { Rate }\left(\mathrm{h}^{-1}\right)\end{array}$ & \pm 1 sigma & $\begin{array}{c}\text { Growth } \\
\text { Rate }\left(\mathrm{h}^{-1}\right)\end{array}$ & \pm 1 sigma \\
\hline \hline 4.0 & 0.009 & 0.002 & 0.006 & 0.001 & 0.003 & 0.001 \\
\hline
\end{tabular}

The results show no change in the reduction rate of $\mathrm{Am}(\mathrm{VI})$ when in contact with dodecane. A comparison of the reduction rates calculated for the same concentration of $4.0 \mathrm{mM}$ Am from tables $3 \& 4$ show that the $A m(V I)$ reduction rates in the absence of dodecane overlap with the observed reduction rate for the system in contact with dodecane. Comparison of the growth rates for Am(V) from data in tables 3 $\& 4$ also show that the production of $\mathrm{Am}(\mathrm{V})$ was not influenced by contact with dodecane. This is an important result since the ultimate goal is to separate Am using solvent extraction, and dodecane is the common diluent in extraction formulations. Qualitative observations have previously shown that organophosphorous ligands such as TBP [11] and DAAP [10] are reducing toward Am(VI), but our unpublished work has suggested that monoamides such as DEHBA may be less so. Future work will measure quantitative americium reduction rates in the presence of these solvent extraction ligands. These results will provide an understanding the reduction pathways for Am(VI) in contact with organic diluents and extractants, of obvious importance in systems where the Am(VI)-containing aqueous phase may undergo multiple stages of organic phase contact.

\subsection{Effect of Cerium on Am(VI) Reduction}

Another factor that may influence Am(VI) stability in real world application is the presence of other redox active metals in solution. Cerium is one such example. A $1.0 \mathrm{mM}$ americium solution was made 5.0 $\mathrm{mM}$ with $\mathrm{Ce}(\mathrm{III})$ in $6.5 \mathrm{M} \mathrm{HNO}_{3}$ and oxidized concomitantly by contact with sodium bismuthate for $2 \mathrm{~h}$ to produce a solution containing $\mathrm{Am}(\mathrm{VI})$ and $\mathrm{Ce}(\mathrm{IV})$. The resulting solution was bright yellow from the $\mathrm{Ce}(\mathrm{IV})$, however, $\mathrm{Ce}(\mathrm{IV})$ absorbance begins at around $550 \mathrm{~nm}$ and did not interfere with $\mathrm{Am}(\mathrm{VI}) / \mathrm{Am}(\mathrm{V})$ absorbances at $999 \mathrm{~nm}, 666 \mathrm{~nm}$ and $718 \mathrm{~nm}$. An example absorption spectrum containing Ce is shown in figure 7. 


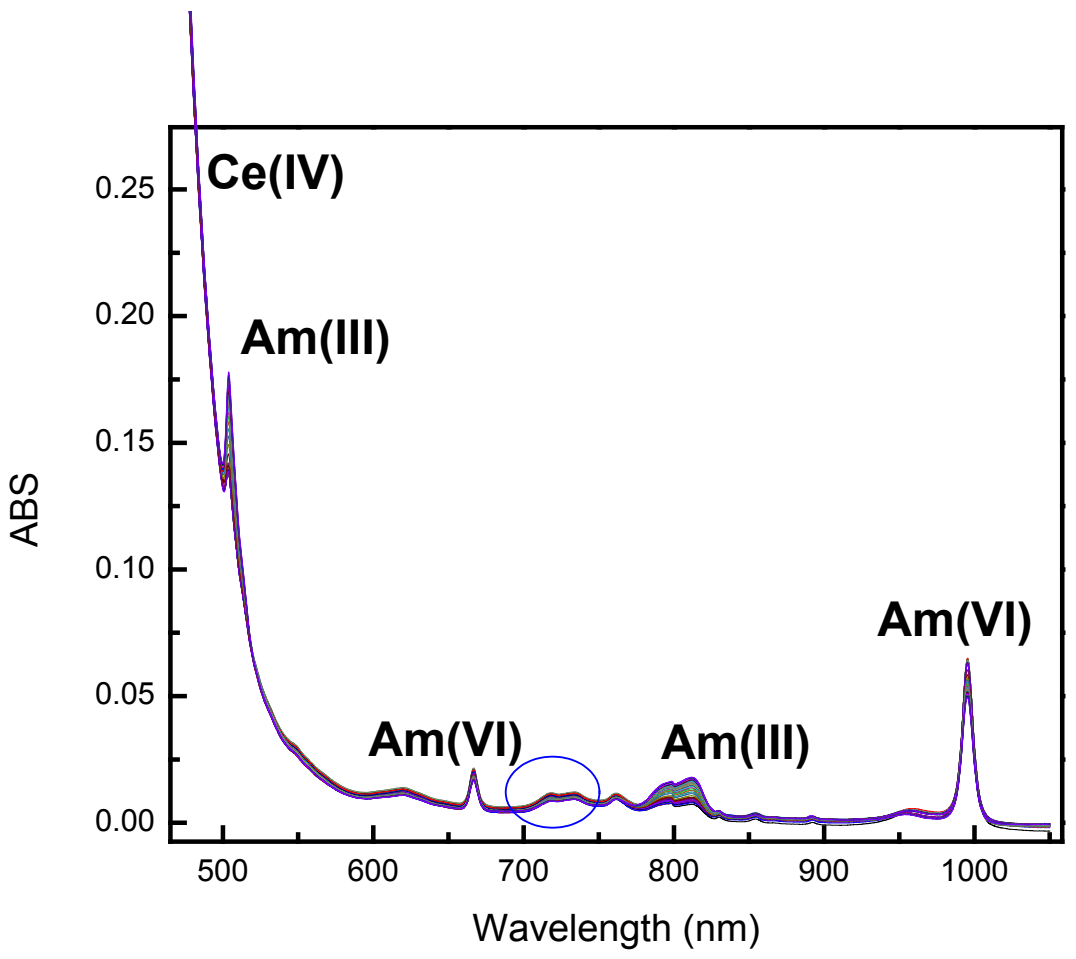

Figure 7. Characteristic absorption spectra for oxidized americium in the presence of Ce(IV). The absorbances represent 1.0 $\mathrm{mM}$ Am and 5.0 $\mathrm{mM}$ Ce in $6.5 \mathrm{M} \mathrm{HNO}_{3}$.

The data show the expected absorbances at $999 \mathrm{~nm}(\mathrm{Am}(\mathrm{VI})), 503 \mathrm{~nm}(\mathrm{Am}(\mathrm{III}))$ and off scale absorbance beginning at $550 \mathrm{~nm}$ for $\mathrm{Ce}(\mathrm{IV})$. The $\mathrm{Am}(\mathrm{VI})$ concentration is seen to decrease with time. It can be seen in table 6 that this reduction is faster than observed in the absence of cerium as reported in tables 2-5. The absorbance peak for $A m(V), 718 \mathrm{~nm}$, showed no change over the $24 \mathrm{~h}$ period of data collection. This result is unexpected and suggests that $\mathrm{Am}(\mathrm{VI})$ reduction in the presence of cerium either bypasses $\mathrm{Am}(\mathrm{V})$, or that produced $\mathrm{Am}(\mathrm{V})$ is re-oxidized. It is probable the $\mathrm{Am}(\mathrm{V})$ is oxidized back to $\mathrm{Am}(\mathrm{VI})$ through the reduction of Ce(IV). This may be explained by taking a simplistic approach to comparing reduction potentials for $\mathrm{Am}$ and $\mathrm{Ce}$. The reduction potential for $\mathrm{AmO}_{2}{ }^{2+} \rightarrow \mathrm{AmO}_{2}{ }^{+}$is $1.6 \mathrm{~V}$ and the reduction potential for $\mathrm{Ce}(\mathrm{IV}) \rightarrow \mathrm{Ce}(\mathrm{III}) 1.76 \mathrm{~V}$. Thus the reaction should be favorable. Additional experiments are currently being conducted with $\mathrm{Am}(\mathrm{V})$ and $\mathrm{Ce}(\mathrm{IV})$ to determine if this pathway is possible. However, the faster reduction of $\mathrm{Am}(\mathrm{VI})$ is unexplained, and deserves continued investigation. Additional experiments will be necessary to determine the reduction pathways for Am in the presence of not only $\mathrm{Ce}$, but additional fission products found in the used fuel matrix. It should be noted that while the rate of Am(VI) reduction has increased, it still has long term stability sufficient for separations.

Table 6. Reduction rates for Am(VI) in the presence of Ce(IV) using a $2 \mathrm{~h}$ time increment. The americium solution contained $1.0 \mathrm{mM} \mathrm{Am} / 5.0 \mathrm{mM}$ Ce in $6.5 \mathrm{M} \mathrm{HNO}_{3}$.

$999 \mathrm{~nm}$

$666 \mathrm{~nm}$

$718 \mathrm{~nm}$

\begin{tabular}{|c|cc|cc|c|}
\hline$[\mathrm{Am}]_{\text {total }}, \mathrm{mM}$ & Reduction Rate $\left(\mathrm{h}^{-1}\right)$ & \pm 1 sigma & Reduction Rate $\left(\mathrm{h}^{-1}\right)$ & \pm 1 sigma & Growth Rate $\left(\mathrm{h}^{-1}\right)$ \\
\hline \hline 1.0 & 0.019 & 0.004 & 0.017 & 0.003 & 0 \\
\hline
\end{tabular}




\section{CONCLUSIONS}

The stability of hexavalent americium was measured using multiple americium and nitric acid concentrations after contact with the strong oxidant sodium bismuthate. Initial studies were conducted to establish contact times to produce the greatest $\mathrm{Am}(\mathrm{VI})$ yield. It was determined that for 1.0 and $3.0 \mathrm{M}$ $\mathrm{HNO}_{3}, 24 \mathrm{~h}$ contacts produced $50 \%$ and $85 \% \mathrm{Am}(\mathrm{VI})$ respectively. The $6.5 \mathrm{M} \mathrm{HNO}_{3}$ systems only required a $2 \mathrm{~h}$ contact to achieve an $85 \%$ yield of $\mathrm{Am}(\mathrm{VI})$. Detectable $\mathrm{Am}(\mathrm{VI})$ persisted for over $48 \mathrm{~h}$ in $1.0 \mathrm{M} \mathrm{HNO}_{3}, 72 \mathrm{~h}$ in $3.0 \mathrm{M} \mathrm{HNO}_{3}$ and $110 \mathrm{~h}$ in $6.5 \mathrm{M} \mathrm{HNO}_{3}$. After a $24 \mathrm{~h}$ contact, the $0.1 \mathrm{M} \mathrm{HNO}_{3}$ system produced $\mathrm{Am}(\mathrm{V})$ exclusively. The shorter necessary contact times for the higher acidities and the failure to produce $\mathrm{Am}(\mathrm{VI})$ in $0.1 \mathrm{M} \mathrm{HNO}_{3}$ demonstrate that the oxidation of $\mathrm{Am}(\mathrm{III})$ to $\mathrm{Am}(\mathrm{VI})$ using sodium bismuthate has a strong proton dependence likely due to the increased solubility of $\mathrm{BiO}_{3}{ }^{-}$in more highly acidic media.

Contrary to our hypotheses Am(VI) was not reduced faster at higher americium concentrations, and the reduction was only zero-order at short time scales. Attempts to model the reduction kinetics using zero order kinetic models showed Am(VI) reduction in nitric acid is more complex than the autoreduction processes reported by others in perchloric acid. In fact, the analyses of these data over long time frames suggest that the kinetics for all the systems studied (regardless of americium or nitric acid concentration) are mixed order with complicating secondary reduction pathways introduced by secondary radiolysis products. The radiolysis products are generated by irradiation of $\mathrm{H}_{2} \mathrm{O}$ and $\mathrm{HNO}_{3}$ by $\alpha$-decay. It appears that over time the longer-lived molecular radiolysis products such as $\mathrm{H}_{2} \mathrm{O}_{2}$ and $\mathrm{HNO}_{2}$ build up in solution and begin to react with the Am species and/or themselves which has a large impact on the overall kinetics. Changes in the linearity of the kinetic models are indicators of additional reactions present in the systems. The data did show that our hypothesis that $\mathrm{Am}(\mathrm{VI})$ is more stable at higher nitric acid concentrations was correct.

The classical zero-order reduction of Am(VI) was found here only for short times on the order of a few hours. However, although zero-order reduction has been attributed to reduction by radiolysis products in the past, we measured no effect of changing americium concentration. We did show that the rate of $\mathrm{Am}(\mathrm{V})$ production was less than the rate of $\mathrm{Am}(\mathrm{VI})$ reduction, indicating that some $\mathrm{Am}(\mathrm{VI})$ undergoes two electron-reduction to Am(IV).

Experiments were also conducted to monitor the Am(VI) reduction in contact with the organic diluent dodecane. A direct comparison of these results with those in the absence of the organic diluent showed the reduction rates for $\mathrm{Am}(\mathrm{VI})$ were not statistically different for both systems. The result is a significant first step in understanding the potential reduction pathways for $\mathrm{Am}(\mathrm{VI})$ in solvent extraction processes since the envisioned separations using higher oxidation states will require multiple contacts with organic diluents and selected extractants.

Americium oxidations were also conducted in the presence of $\mathrm{Ce}(\mathrm{IV}) / \mathrm{Ce}(\mathrm{III})$ ions. These results showed that $\mathrm{Am}(\mathrm{VI})$ is reduced without the typical growth of $\mathrm{Am}(\mathrm{V})$ observed in the systems sans Ce ion. This was an interesting result which suggests a potential new reduction/oxidation pathway for Am in the presence of Ce. Currently, these results are very preliminary. Surprisingly, it also appears that the Am(VI) reduction rate was increased by a factor of 2 in the presence of Ce ion. The mechanism by which this would occur is not understood. 
Overall these studies have shown that hexavalent americium is fundamentally stable enough in nitric acid to run a separations process. However, the complicated nature of the reduction pathways based on the system components is far from being rigorously understood. Additional studies will be needed before an understanding of the fundamental redox chemistry of americium is completely understood. Future work will examine the effects of extractants and other raffinate constituents on Am(VI) stability, as well as added alpha emitters to increase the alpha dose rate, but not the Am concentration. 


\section{REFERENCES}

1. Asprey, L.B.; Stephanou, S.E. 1950, The autoreduction of Am(VI) and Am(V). United States Atomic Energy Commission Report AECU-924. Los Alamos Scientific Laboratory.

2. Hall, G.R.; Markin, T.L. 1957, The self-reduction of americium(V) and (VI) and the disproportionation of americium(V) in aqueous solution. J. Inorg. Nucl. Chem. 4: 296-303.

3. LaVerne, J.A. 2004, in: Mozumder, A.; Hatano, Y. Charged particle and photon interactions with matter. Marcel Dekker, New York, pp 403-429.

4. Woods, Sr. M.; Cain, A.; Sullivan, J.C. 1974, A kinetic study of the reduction of americium (VI) by hydrogen peroxide in aqueous perchlorate media. J. Inorg. Nucl. Chem. 36:2605-2607.

5. Zaitsev, A.A.; Kosyakov, V.N.; Rykov, A.G.; Sobolev, Yu.P.; Yakovlev, G.N. 1960, Kinetics of americium (V) reduction by hydrogen peroxide. Radiokhimiya 2:348-350.

6. Mincher, B.J.; Schmitt, N.C.; Case, M.E. 2011, A TRUEX-based separation of americium from the lanthanides. Solvent Extr. Ion Exch. 29:247-259.

7. Katsumura, Y. 1998, in: Alfassi, Z.B. N-Centered radicals. John Wiley and Sons, New York. Pp. 393-412.

8. Precek, M.; Paulenova, A.; Tkac, P.; Knapp, N. 2010, Effect of gamma irradiation on the oxidation state of neptunium in nitric acid and in the presence of selected scavengers. Sep. Sci. Technol. 45:1699-1705.

9. Mincher, B.J.; Precek, M.; Mezyk, S.P.; Elias, G.; Paulenova, A. 2013, The redox chemistry of neptunium in $\gamma$-irradiated aqueous nitric acid. Radiochim. Acta 101:259-265.

10. Mincher, B.J.; Martin, L.R.; Schmitt, N.C. 2012, Diamylamylphosphonate solvent extraction of $\mathrm{Am}(\mathrm{VI})$ from nuclear fuel raffinate simulant. Solvent Extr. Ion Exch. 30:445-456.

11. Mincher, B.J.; Martin, L.R.; Schmitt, N.C. 2008, Tributylphosphate extraction behavior of bismuthate-oxidized americium. Inorg. Chem. 47:6984-6989.

12. Woods, Sr., M.; Cain, A.; Sullivan, J.C. 1974, A kinetic study of the reduction of americium(VI) by hydrogen peroxide in aqueous perchlorate media. J. Inorg. Nucl. Chem. 36, 2605-2607.

13. Dares, C.J.; Lapides, A.M.; Mincher, B.J.; Meyer, T.J. Electrochemical oxidation of ${ }^{243}$ Am(III)in nitric acid by a terpyridyl-derivatized electrode. Submitted to Science. 2015. 